\title{
Estudio de las encuadernaciones tipo a la catedral de la Real Academia de la Historia
}

\section{Study of type bindings to the cathedral of the Royal Academy of History}

\section{Antonio Carpallo Bautista}

acarpall@ucm.es

Universidad Complutense de Madrid

\author{
Juan Bautista Massó Valdés
}

juanbautista.masso.valdes@madrid.org

Biblioteca Pública Villa de Vallecas "Luis Martín Santos" (Madrid)

\section{Resumen}

El estilo a la catedral es una de las variantes decorativas románticas que se produjeron a partir de 1820 en Francia por Joseph Thouvenin. A partir de ese momento, se realizaron ornamentaciones con estas planchas en otros países, entre ellos España, donde destacaron encuadernadores como Antonio Suárez, Pedro Pastor, Tomás Cobo y el taller de Ginesta. El presente trabajo trata de estudiar cada una de las encuadernaciones de este tipo decorativo depositadas en la Biblioteca de la Real Academia de la Historia, haciendo hincapié en los materiales, técnicas de construcción y decoración y el estado de conservación, además de estudiar e identificar los antiguos poseedores y los talleres de encuadernación por medio de los hierros y planchas. Para lograrlo se ha realizado un inventariado de todas las encuadernaciones de la Real Academia, seguido de una selección y digitalización de las encuadernaciones estilo a la catedral, para posteriormente realizar el estudio individual de cada ejemplar, facilitando la identificación de encuadernaciones similares, firmadas o no, y marcas de propiedad que se encuentren en otras instituciones.

\section{Palabras clave}

Estilo a la catedral; Estilo romántico; Encuadernación artística; Encuadernadores; Marcas de propiedad; Siglo XIX 


\section{Abstract}

The style to the cathedral is one of the romantic decorative variants that were produced from 1820 in France by Joseph Thouvenin. From that moment ornamentations with these plates were made in other countries, among them Spain, where they highlighted bookbinders such as Antonio Suárez, Pedro Pastor, Tomás Cobo and the Ginesta workshop. The present work tries to study each one of the bindings of this decorative type deposited in the Library of the Royal Academy of the History, emphasizing in the materials, techniques of construction and decoration and the state of conservation, besides studying and identifying the former owners and bookbinding workshops by means of irons and plates. To achieve this objective an inventory of all the bindings of the Royal Academy has been carried out, followed by a selection and digitalization of the style bindings to the cathedral, in order to later carry out the individual study of each copy, facilitating the identification of similar bindings, signed or not, and ownership marks that are found in other institutions..

\section{Keywords}

The style to the cathedral; The style romantic; Artistic bookbinding; Bookbinders; Ownership Mark; 19th century

Recibido: 11/09/2018

Aceptado: 5/12/2018

DOI: https://dx.doi.org/10.5557/IIMEI9-N17-045073

Descripción propuesta: Carpallo Bautista, Antonio; Massó Valdés, Juan Bautista, 2018. Estudio de las encuadernaciones tipo a la catedral de la Real Academia de la Historia. Métodos de Información, 9(17), 45-73

\section{Introducción}

La Biblioteca de la Real Academia de la Historia, a pesar de tener una colección destacable de encuadernaciones artísticas, tanto en su aspecto cualitativo como cuantitativo, no dispone de un estudio exhaustivo e integral de estas. 
No hemos encontrado documentación que muestre la procedencia y la identificación de las marcas de propiedad y quiénes fueron los artesanos responsables de la construcción y la decoración de sus encuadernaciones. Además, la información que aparece sobre las encuadernaciones de sus obras es muy escasa, tanto en el catálogo automatizado como en los diversos catálogos impresos existentes, lo que dificulta saber si el ejemplar se encuentra revestido ornamentalmente.

Otro punto importante a tener en cuenta, es la dispersión de las encuadernaciones por toda la biblioteca. Ya que se encuentran diseminadas dentro de las diferentes colecciones y fondos que conforman la biblioteca. La cual tiene entre sus fondos una colección de encuadernaciones artísticas muy rica y de gran valor patrimonial, histórico y documental, tanto por su diversidad ornamental como por sus procedencias. Su colección está compuesta desde encuadernaciones árabes con solapas, hasta encuadernaciones realizadas por Emilio Brugalla, pasando por ejemplares de tipo mudéjar, de estilo neoclásico y a la catedral, entre otros muchos motivos decorativos.

El estudio de la encuadernación siempre ha ido ligado a la historia del libro, imprescindible para su conservación y desde siempre empleado como lugar de expresión artística, aunque desgraciadamente no se han realizado grandes investigaciones y en la Real Academia de la Historia menos aún. Podemos decir que partimos de cero cuando comenzamos a inventariar las encuadernaciones de esta biblioteca en 2012. Sólo encontramos el Catálogo de la Sección de Códices de la Real Academia de la Historia de la profesora Elisa Ruiz (1997) donde se describe someramente la encuadernación pero sobre los códices medievales. También consultamos un artículo de María Victoria Alberola Fioravanti (1996), exdirectora de la Biblioteca de la Real Academia de la Historia, publicado en la revista Encuadernación de arte, sobre las encuadernaciones mudéjares y renacentistas de la Biblioteca de la Real Academia de la Historia.

A partir de 2012 comenzamos el estudio de las encuadernaciones de la Biblioteca, dando como resultado diversos trabajos, como una tesis doctoral ${ }^{1}$

\footnotetext{
${ }^{1}$ Este artículo está dentro del proyecto de investigación del Ministerio de Economía, Industria y Competitividad, titulado "La encuadernación española en las Reales Academias:
} 
la publicación sobre las encuadernaciones de Emilio Brugalla (García Herranz y Carpallo Bautista 2015), las encuadernaciones de las Guías de Forasteros (Carpallo Bautista et al. 2015), las encuadernaciones medievales (Carpallo Bautista y Esteban García 2017), además de un artículo sobre las encuadernaciones de tipo imperio (Massó Valdés y Carpallo Bautista 2017).

Sobre las encuadernaciones a la catedral se han realizado en España algunas monografías (Carpallo Bautista, 2015) y capítulos (Carrión Gútiez 1996, Capela Martínez 1963), pero sobre todo en Francia, cuna de este tipo ornamentaciones (Beraldi 1895, Culot 2000, 1997, Devaux 2015, Gilles 2014).

Con este trabajo subsanamos, en la medida de lo posible, el estudio de las encuadernaciones a la catedral custodiadas en la Biblioteca de la Academia, analizando los materiales empleados, las técnicas de construcción utilizadas, las estructuras y los motivos decorativos, al igual que el estado de conservación. Establecemos así, una descripción integral de cada encuadernación, con el objetivo de preservar y difundir este patrimonio documental.

\section{Metodología}

Para el estudio de las encuadernaciones la metodología que seguimos en la investigación consistió en la realización de un inventario de las encuadernaciones artísticas de la Biblioteca de la Real Academia de la Historia.

A continuación, procedimos a la selección de las encuadernaciones tipo a la catedral y a la recogida de datos mediante una ficha tipo de descripción, ya empleada en anteriores proyectos de catalogación de encuadernaciones. Esta ficha tipo se divide en tres áreas: Área de responsabilidad y procedencia de la encuadernación, Área de descripción de la encuadernación y Área de descripción del cuerpo del libro. En la primera área identificamos el nombre del encuadernador y la fecha de la encuadernación, tomamos las dimensiones del libro en milímetros (alto $\mathrm{x}$ ancho $\mathrm{x}$ grosor), si conocemos su procedencia (anteriores poseedores $\mathrm{y}$

encuadernadores, talleres y tipologías ligatorias (S. XVIII-XX)" (HAR2017-83387-P) y de la Tesis Doctoral defendida por Juan Bautista Massó Valdés en la Universidad Complutense de Madrid. 
propietarios), la signatura donde se encuentra ubicado dentro del fondo y el estilo decorativo. El Área de descripción de la encuadernación es la más importante porque aquí incluimos el análisis exhaustivo de cada encuadernación estudiando los materiales utilizados, las técnicas de encuadernación, la decoración que contiene y su estado de conservación. Finalmente en el Área de descripción del cuerpo del libro, es donde recogemos los datos puramente bibliográficos de la obra encuadernada, como son el autor, el título de la obra, el lugar de publicación, el editor y el año de publicación, entre otros.

\section{El estilo a la catedral}

La encuadernación a la catedral, también llamado estilo neogótico, agrupado dentro de las encuadernaciones románticas, comienza a conocerse en Francia aproximadamente en 1820. Su creador fue Joseph Thouvenin, que intenta imitar los motivos de las arquerías, ventanales, balaustradas y rosetones de las catedrales góticas. Las composiciones que se emplean son muy variadas, desde las grandes portadas o rosetones de las catedrales góticas, gofrados, dorados o con mosaicos policromados, hasta estos mismos elementos empleados como rellenos de los lomos y de los ángulos de las tapas, uniéndose en muchas ocasiones estas pequeñas y grandes planchas que se estampan con prensas de volante. Estas planchas ocupan casi la totalidad de la superficie de la tapa, encuadradas con unos simples filetes gofrados o dorados y adornados con alguna pequeña flor. Los encuadernadores y otros artesanos emplearon los motivos del estilo alemán (gótico) y reprodujeron sobre las tapas de los libros la ornamentación ya existente: un portal, un interior de catedral, una bóveda de crucería, un altar, pilares, ventanas..., y cubren el centro de la tapa, mientras que arcadas, columnitas, nichos, balaustradas, rosetones con vidrieras, gárgolas o columnas y flores de contornos sinuosos proporcionan los modelos para los encuadramientos.

Técnicamente la decoración a la catedral se caracterizó por la utilización de grandes planchas que se aplicaron con oro o gofradas. Esta técnica se apoya en herramientas como la prensa de volante. Las planchas decoraban casi siempre el centro de la cubierta, y no era extraño verlas encuadradas por uno o varios filetes o con líneas gofradas en seco, que recuerdan el estilo imperio. Junto a las planchas que llenaban casi completamente la superficie de la tapa, 
solían aplicarse a mano pequeños hierros, sobre todo follajes. Para encuadernaciones de lujo se utilizaron mosaicos de colores vivos aplicando trozos de pieles de diferentes colores o bien pintando diseños que reproducían efectos de policromía.

En España este estilo se comienza a emplear en la decoración de las encuadernaciones a finales del reinado de Fernando VII (1814-1833) y se desarrolla con Isabel II (1833-1868). En comparación con las de los encuadernadores franceses, en nuestro país no se hicieron obras de gran formato, siendo lo habitual en España que este tipo de decoraciones se empleara sobre libros de pequeño tamaño en los que era muy frecuente el empleo de planchas en el centro. Estos elementos decorativos se dejaban para las esquinas, con pequeños rosetones y ojivas, dejando el centro de la tapa para una plancha romántica o un motivo heráldico.

Durante el siglo XIX encontramos a encuadernadores como Gabriel de Sancha, junto a su hijo Indalecio (López Serrano 1975), Antonio Suárez, Santiago Martín (López Serrano 1943) y Tomás Cobo en las primeras décadas y a la familia Ginesta, con Miguel Ginesta Clarós (padre), Miguel Ginesta de Haro (hijo) y Miguel Ginesta Revuelta (nieto) ya en la segunda mitad de siglo. También trabajaron para la Academia otros encuadernadores como Antonio Baylo, Juan Bot, Miguel de Burgos (Ayudante y después Regente del taller de Joaquín Ibarra), Manuel Novillo y la Imprenta Nacional, que también recibió encargos.

El encuadernador más relevante que realizó este tipo de ornamentaciones fue Antonio Suárez Jiménez, que a partir del año 1831, revistió con este tipo de decoración y sobre piel marroquín bastantes ejemplares, que se pueden reconocer porque incluían la cifra real de Fernando VII (Carpallo Bautista 2015, López Serrano 1942).

La Biblioteca de la Real Academia de la Historia contiene once ejemplares de tipo a la catedral, de los cuales seis son Guías de Forasteros (sig. 21/1841, 21/1842, 21/1843, 3385/1840-1 y 19-2/510), esta última procede del Fondo Príncipe Pío; dos pertenecen a la colección del marqués de San Román (sig. 2/1531 y 1/2987); una está incluida en el Fondo Ángel Ferrari (sig. 23/15579); mientras el resto se encuentran en diferentes ubicaciones de la 
biblioteca. Una característica decorativa común en todas ellas, es la estampación de una plancha gofrada, que ocupa toda la superficie del plano de la tapa. Esta plancha puede estar enmarcada por una orla dorada de motivos sencillos. Las técnicas decorativas que se suelen emplear en las estampaciones de este tipo son fundamentalmente el gofrado, a través de la estampación de grandes planchas de cobre con motivos de catedrales góticas como hemos visto con anterioridad. También se pueden combinar con motivos e hilos dorados en forma de ruedas sencillas en la orla exterior. La yuxtaposición de estas dos técnicas la observamos en la sig. 1/2987, envuelta en terciopelo rojo, con una plancha estampada en seco y los supra libros dorados "E.F.S.R." (Eduardo Fernández San Román, como propietario), en la parte central de la plancha.

\section{Estudio de las encuadernaciones}

Uno de los aspectos a analizar de este grupo de encuadernaciones es el tipo de los materiales utilizados en la construcción. El estudio nos indica que las tapas de todas las encuadernaciones son de cartón, recubiertas cinco de ellas de piel, al igual que el lomo (sig. 19-2/510, 3/7027, 2/1531, 3/8814 y 23/15579), otras cinco de tafilete (sig. 3385/1840-1, 21/1841, 21/1843, 21/1838-2 y $21 / 1842$ ) y una de terciopelo (sig. 1/2987), siendo este un material muy frágil a la exposición de la luz y al uso; las guardas también son de diferentes materiales, como los papeles verjurados marmoleados tipo Shell (sig. 19-2/510 y 3/7027), papeles verjurados marmoleados tipo plegado español (3385/1840-1, 21/1841, 21/1843, 2/1531, 21/1838-2 y 21/1842), moaré (sig. 1/2987 y 3/8814), papel blanco con fondo punteado (sig. 23/15579 y 21/1842); los cortes están dorados con pan de oro (sig. 19-2/510, 1/2987, 3/7027, 23/15579 y 3/8814), pintado de color amarillo (sig. 3385/1840-1 y 21/18382), de color marrón (sig. 2/1531); todos los nervios son de cordel de fibra vegetal.

Respecto a la estructura constructiva, las tapas están encartonadas (sig. 1/2987, 3/7027, 23/15579, 2/1531 y 3/8814) o las tapas son sueltas (sig. 192/510, 3385/1840-1, 21/1841, 21/1843, 21/1838-2 y 21/1842), mediante tres nervios sencillos, con un cosido a punto seguido y a la greca (sig. $1 / 2987$, $3 / 7027,23 / 15579,2 / 1531$ y $3 / 8814$ ), y otros con un cosido a punto salteado 
(sig. 19-2/510, 3385/1840-1, 21/1841, 21/1843, 21/1838-2 у 21/1842), todos con el lomo liso y redondeado; las guardas están realizadas con la técnica del marmoleado, que consiste es traspasar la pintura al papel a través del contacto de un líquido mucilaginoso contenido en una cubeta (sig. 23/17423, 3/3337, 3/3338, 13/3104, 14/11113).

En cuanto a las marcas de propiedad y antiguos poseedores encontramos una etiqueta impresa en la guarda anterior con el exlibris "BIBL / ARCH", procedente del Fondo Príncipe Pío, el cual había pertenecido a Alfonso de Falco y de la Gándara, Príncipe Pio de Saboya ${ }^{2}$ (sig. 19-2/510).

También en la guarda anterior de otras dos encuadernaciones aparece el sello de "Biblioteca-E.F. San Román”3, y en la portada se muestra estampado el sello "R. Academia de la Historia-Biblioteca-San Román" (sig. 1/2987 y 2/1531) junto a la firma de José de Espronceda (sig. 1/2987).

Otras marcas de propiedad corresponden a la Biblioteca Adolfo Herrera ${ }^{4}$ que aparece en la guarda anterior (sig. 3385/1840-1).

La última de las marcas de propiedad que encontramos en estas encuadernaciones es un sello estampado en la portada con la leyenda "Real Academia de la Historia-Fondo Ángel Ferrari”’ (sig. 23/15579).

\footnotetext{
${ }^{2}$ Alfonso de Falco muere en Zúrich el 3 de mayo de 1967 y su colección de libros es donada a la Real Academia de la Historia, tal y como se indica en el Boletín de la Real Academia de la Historia, n. ${ }^{\circ}$ 170-171, del año 1973, p. 280: "Nuevo generoso donante fue don Alfonso Falcó de la Gándara, Príncipe Pio, Marqués de Castel Rodrigo y otros titulos, favoreciendo a la Biblioteca con un copioso centón de obras, especialmente genealógicas, italianas gran parte de las mismas, con las cuales no contaban nuestros ficheros, lo cual debe acrecer nuestra gratitud a la memoria de dicho prócer y a su viuda, doña Sueva-Victoria Colonna, quien, diligente y amabilísimamente, cumplimentó la voluntad de su esposo".
}

${ }^{3}$ Eduardo Fernández San Román obtuvo el título de marqués de San Román en 1879. Fue un importante bibliófilo y coleccionista, legó a la Academia su biblioteca en marzo de 1888 en virtud de legado testamentario. Su contenido está formado por 7.826 impresos y 160 manuscritos de varias materias (385 autógrafos de variadas personalidades reunidas en 8 cajas- 36 incunables- 19 cajas de folletos) especialmente de arte militar, además de valiosos autógrafos. Es una de las colecciones más ricas que posee la Academia, con cuidadas encuadernaciones.

${ }^{4}$ Adolfo Herrera fue un bibliófilo y académico de la Real Academia de la Historia que al morir (Madrid, 1925) dona a la Academia un valioso fondo documental incluyendo sus papeles de trabajo sobre Numismática, epigrafía y arqueología así como cartas y manuscritos diversos. 
Respecto a los encuadernadores, el análisis de las planchas empleadas, los tipos de las leyendas de los tejuelos, el tipo de ornamentación de las guardas y el estudio comparativo con encuadernaciones similares depositadas en otras instituciones, nos indican que algunas de las encuadernaciones fueron realizadas por el taller de Ginesta: seis de ellas (sig. 19-2/510, 3385/1840-1, 21/1841, 2/1843, 1/2987 y 3/7027), por Miguel Ginesta Clarós (1790-1853), y una (sig. 23/15579) por Miguel Ginesta de Haro (1820-1878). Finalmente no encontramos ninguna del último miembro de la saga Miguel Ginesta Revuelta (1858?-).

De entre las planchas empleadas en el taller de Ginesta, se muestran dos similares como las signaturas $1 / 2987$ y $3 / 7027$ y otra con pequeñas variantes en el inferior de la plancha (sig. 19-2/510). Encontramos tres planchas análogas con variantes en su terminación pero con una estructura semejante, como la plancha de la signatura $23 / 15579$, con la parte central de la ventana y la parte inferior libre de decoración; una plancha gofrada muy similar a ésta y posiblemente del mismo encuadernador, se encuentra en la Biblioteca del Ayuntamiento de Madrid, sig. R. 708. La encuadernación con signatura 3385/1840-1 contienen una plancha similar a la anterior con la ventana libre de decoración pero con ornamentación en la parte inferior, y por último, las encuadernaciones con signaturas 21/1841 y 2/1843, las dos más completas, con ornamentación en la parte inferior de la plancha y un enrejado, simulando las puerta de una ventana en la parte central.

Siguiendo con el estudio de planchas, la plancha central estampada en seco en la Guía de Forasteros del año 1842 (sig. 21/1842) guarda muchas similitudes con

${ }^{5}$ Don Ángel Ferrari Núñez. Su biblioteca particular es muy importante, pudiendo alcanzar los 30.000 volúmenes, sumados libros, folletos y revistas. Extraemos del Boletín Corporativo de la Real Academia de la Historia, Tomo CLXXX, Año 1983, p. 233, la siguiente información: "Destacamos que el Numerario Excmo. Señor don Angel Ferrari Núñez, Catedrático jubilado de Historia de la Edad Media, de la Facultad de Filosofía y Letras de la Universidad de Madrid, poseedor de caudalosa biblioteca, personal e inteligentemente reunida a lo largo de su existencia, ha tenido el gran desprendimiento de donarla en su literalidad, y sin condicionamiento alguno, a esta misma Real Academia, a la que pertenece desde bace veinticinco años, sirviéndola con asidua fidelidad y con el fervor que significativamente traduce hoy tan espontánea decisión del ilustre académico, a quien llega el hondo y unánime reconocimiento corporativo por dicho desprendimiento, que tanto beneficio ha de rendir a los estudiosos. La Real Academia, en total acuerdo, elevó al Excmo. Señor Ministro de Cultura solicitud de ingreso de don Angel Ferrari en la Orden Civil de Alfonso X el Sabio, con categoría de Gran Cruz". 
otra encuadernación de la Biblioteca de la Real Academia de Bellas Artes de San Fernando (sig. C-1879).

También es posible indicar la autoría de Pedro Pastor en la encuadernación (sig. 21/1838-2) realizada sobre 1838, con hierros del taller de Antonio Suárez Jiménez. Esta plancha la podemos encontrar, con pequeñas variantes, en dos encuadernaciones custodiadas en la Real Biblioteca (sig. XIV/2911 y I/I/290), realizadas por el encuadernador Antonio Suárez Jiménez, y que parte de su taller pasa al morir en 1836 a Pedro Pastor.

Para terminar con la correspondencia de planchas en otras encuadernaciones, indicar que la plancha de la encuadernación (sig. 3385/1840-1) es similar a la que encontramos en la Real Biblioteca (sig. CS/4/1) del año 1839, siendo realizada por Miguel Ginesta Clarós a finales de 1939 o primeros de 1840. La última correspondencia la encontramos en la plancha de la encuadernación (sig. 21/1841) similar a otra custodiada en la Real Biblioteca (sig. CS/4/2) del año 1842, siendo realizada la de la Real Academia por Miguel Ginesta Clarós a finales de 1840 o primeros de 1841.

Comenzando con el estudio, la primera de estas encuadernaciones contiene la obra Calendario y guía de forasteros en Madrid, para el año de 1836, encuadernada por Miguel Ginesta Clarós, muy posiblemente a finales de 1835 o primeros de 1836. Las dimensiones de la encuadernación son 120 × 77 × $30 \mathrm{~mm}$. y el volumen forma parte del Fondo Príncipe Pío siendo su signatura 19-2/510. En la guarda anterior aparece la etiqueta con el exlibris "BIBL / ARCH", procedente del Fondo Príncipe Pío, el cual había pertenecido a Alfonso de Falco y de la Gándara, Príncipe Pio de Saboya, XVI marqués de Castel Rodrigo. 

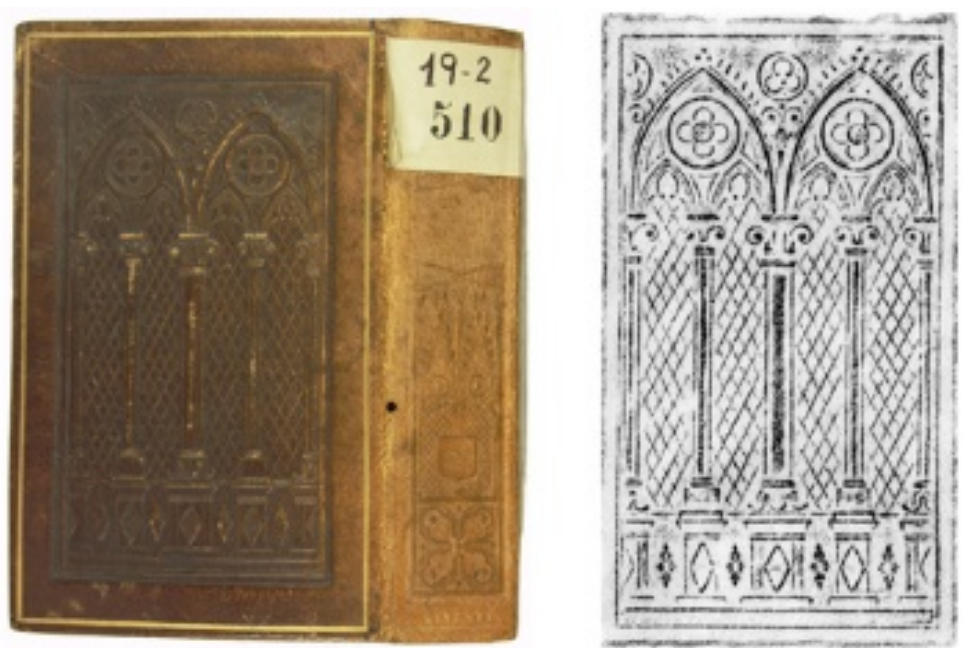

Fig. 1. Tapa posterior y lomo y frotis de la plancha

El estudio de los materiales empleados nos indica que las tapas son de cartón y están recubiertas de piel color marrón, al igual que el lomo, las guardas son de papel verjurado y están marmoleadas con colores azul, gris, negro, amarillo y rojo, los nervios son de cordel de fibra vegetal y los cortes están decorados con pan de oro.

En cuanto a las técnicas de construcción, las tapas no están encartonadas sino que son sueltas, el lomo está liso, el cosido está realizado con la técnica denominada a punto salteado o a la francesa y las guardas están marmoleadas ${ }^{6}$ mediante el traspaso por el contacto de la pintura en la superficie de un líquido mucilaginoso.

La estructura decorativa de las tapas es simétrica y se compone de una bordura exterior de un hilo dorado y una plancha gofrada de tipo a la catedral (98 x $55 \mathrm{~mm}$.), que ocupa toda la superficie de la tapa, decorada con dos grandes ventanales en el centro. Los utensilios empleados han sido una plancha y una rueda y las técnicas decorativas el gofrado y el dorado.

\footnotetext{
${ }^{6}$ Esta técnica se produce al sumergir el papel en un líquido mucilaginoso dentro de una cubeta de madera o metal.
} 

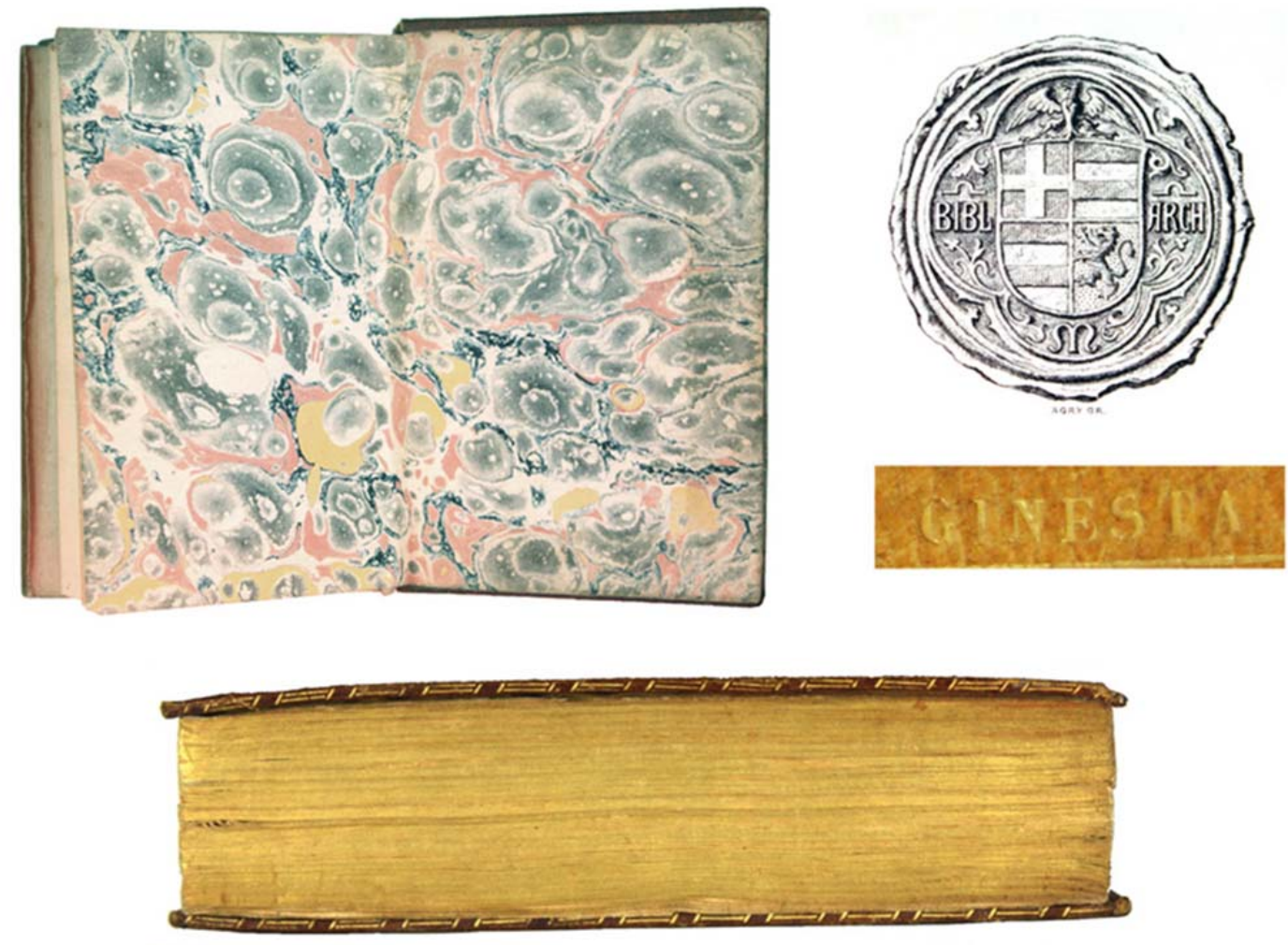

Fig. 2. Guarda posterior, exlibris de Alfonso de Falco, firma del encuadernador y corte delantero

El diseño de las guardas forma parte del grupo denominado gotas y del modelo Shell o concha. El lomo está decorado con una plancha tipo a la catedral gofrada con la leyenda "GUIA / DE / FORASTEROS", el año "1836” y el nombre del encuadernador en la parte inferior "GINESTA", todo ello dorado. Los cantos están decorados con una rueda dorada de dobles filetes alternados con un filete inclinado. Los cortes están dorados.

El estado de conservación es bueno, sin embargo, presenta deformación en las puntas, abrasiones en el lomo y cantos. El lomo está desprendido del cuerpo del libro.

La siguiente encuadernación del estudio contiene la obra Poesias de D. José de Espronceda, impresa en Madrid por la imprenta de Yenes en 1840. Sus dimensiones son 211 x 136 × $37 \mathrm{~mm}$., su signatura es $1 / 2987$ y forma parte de

\footnotetext{
${ }^{7}$ Este diseño consiste en dejar la pintura tal y como cae en el líquido sin intervención posterior, añadiendo unas gotas de aceite de oliva al último color, haciendo aparecer un halo blanco alrededor de cada gota.
} 
la Biblioteca Marqués de San Román. Esta encuadernación posiblemente fue realizada por Miguel Ginesta Clarós sobre 1840.
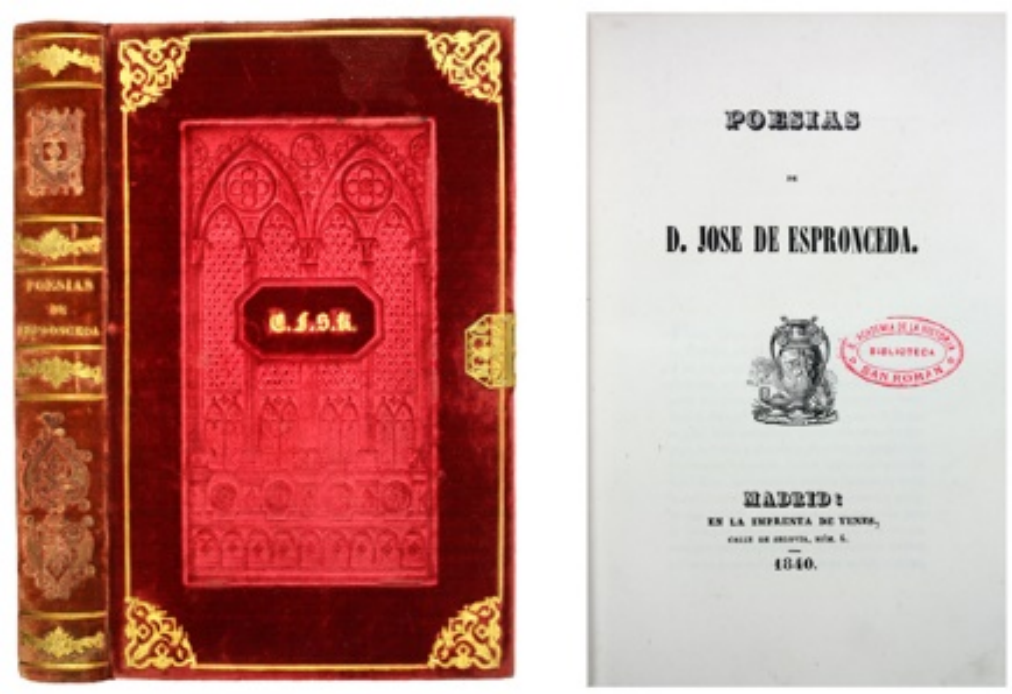

Fig. 3. Tapa anterior y lomo y portada

En cuanto a los materiales de construcción en las tapas se ha empleado cartón recubierto de terciopelo de color rojo, al igual que el lomo, las guardas son de seda, los nervios son de cordel de fibra vegetal; el núcleo de las cabezadas es una tira de cordel de fibra vegetal recubierta de tela a rayas rojas, los cortes están dorados con pan de oro y el cierre es de latón dorado.

El análisis de las técnicas de construcción nos indica que las tapas están encartonadas mediante tres nervios sencillos, con un cosido a punto seguido y a la greca, el lomo es liso y está redondeado, las cabezadas están adheridas al lomo.

Respecto a la decoración indicar que la estructura de las tapas es simétrica y están decoradas por un encuadramiento exterior formado por una orla dorada de hilo sencillo con un florón estilizado en las esquinas. La parte central está decorada con una plancha a la catedral $(146 \times 82 \mathrm{~mm}$.) y las iniciales de Eduardo Fernández, marqués de San Román, en dorado. Los utensilios empleados han sido una rueda, un florón y una plancha y las técnicas de decoración han sido el dorado y el estampado en seco. Las guardas están decoradas con seda de color hueso. El lomo está decorado con diferentes hierros románticos estampados en seco y dorados, dispuestos en horizontal como en vertical. El tejuelo contiene la leyenda: "POESIAS / DE / 
ESPRONCEDA". El cierre está decorado con motivos vegetales, rameados y flores redondeadas. Las cabezadas están decoradas con el recubrimiento de tela blanca con rayas de color rojo. Los cortes están decorados con pan de oro.

La encuadernación se encuentra en buen estado. En la guarda anterior aparece el sello de "Biblioteca-E.F. San Román", en la portada estampado el sello "R. Academia de la Historia-Biblioteca-San Román” y la firma de José de Espronceda.

La siguiente de las encuadernaciones que hemos estudiado contiene la obra Resumen bistórico del Arma de Ingenieros en general, y de su organización en España, impresa en Madrid por la Imprenta Nacional en 1846. Sus dimensiones son 184 x 121 x $20 \mathrm{~mm}$. y su signatura es 3/7027. En la portada estampado en el sello de "Real Academia de la Historia-Biblioteca".

El análisis nos indica que las tapas son de cartón recubiertas de piel de color rojo, al igual que el lomo, las guardas son de papel de fondo blanco con pintura de color marrón, verde y blanco, los nervios son de cordel de fibra vegetal, el núcleo de las cabezadas es una tira de cordel de fibra vegetal recubierta de tela y los cortes están realizados con pan de oro.
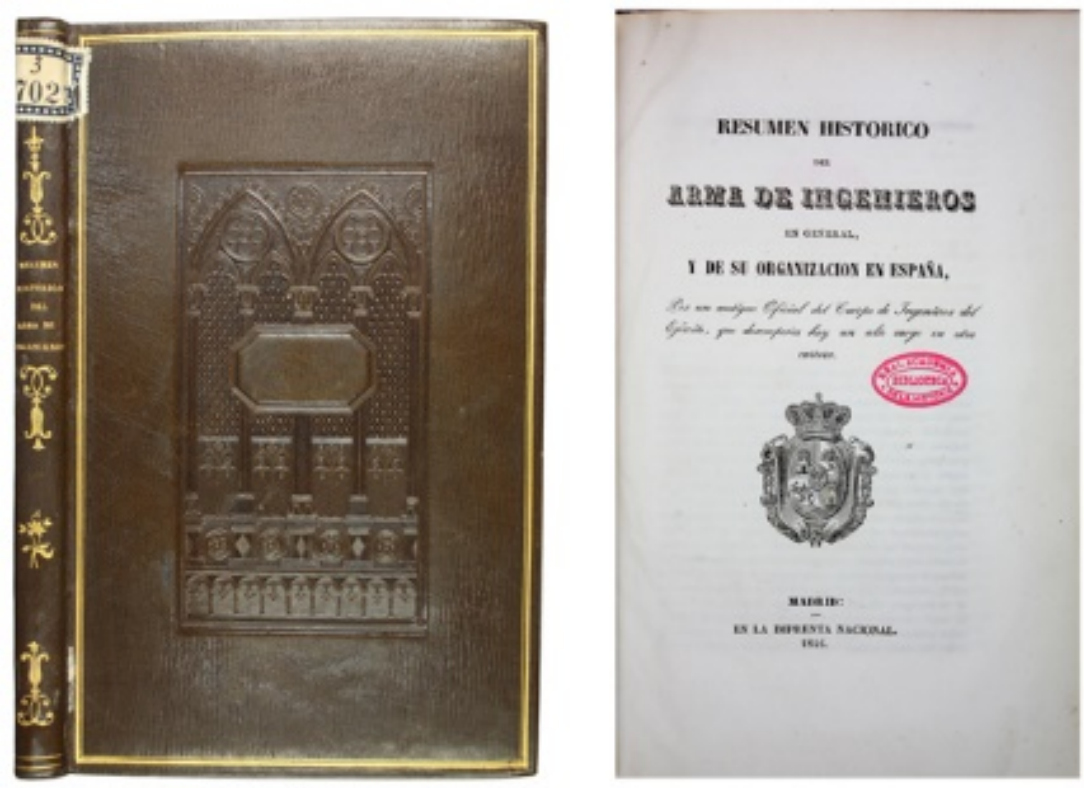

Fig. 4. Tapa anterior y lomo y portada 
En cuanto a las técnicas constructivas las tapas están encartonadas mediante tres nervios sencillos, con un cosido a punto seguido y a la greca, el lomo es liso y está redondeado, las cabezadas están pegadas al lomo, las guardas están realizadas siguiendo la técnica del marmoleado, que consiste en el traspaso de pintura de color al papel, a través de una superficie con un líquido mucilaginoso contenido en una cubeta.

Las tapas son simétricas y están decoradas con un encuadramiento exterior compuesto por una orla de doble hilo dorado, uno de mayor grosor que el otro. La parte central está decorada con una plancha gofrada a la catedral (150 x $90 \mathrm{~mm}$.). Los utensilios empleados han sido una rueda y una plancha y las técnicas de decoración el dorado y el gofrado. Las guardas están decoradas siguiendo el grupo gotas modelo Shell, también denominado concha o caparazón. El lomo está decorado con hierros sueltos dorados, redondeados y de motivos florales, y una flor de dos tallos largos con hojas. El tejuelo contiene la leyenda: "RESUMEN / HISTORICO / DEL / ARMA DE / INGENIEROS". La cabeza y pie de imprenta están decorados con un doble hilo dorado. Los cantos están decorados con una rueda dorada de hilos en zigzag, los contracantos con una rueda dorada de postas y rombos separados y la cofia con una paleta dorada de hilos en zig-zag. Las cabezadas están decoradas con el recubrimiento de tela. Los cortes están dorados. La encuadernación se encuentra en buen estado.

Las planchas centrales de las dos encuadernaciones anteriores son similares, lo que nos hace pensar que fueron realizadas en el mismo taller de encuadernación, muy posiblemente en el taller de Miguel Ginesta Clarós.

La siguiente encuadernación del estudio contiene la obra Guía de forasteros en Madrid, para el año de 1840, igualmente realizada por Miguel Ginesta Clarós a finales de 1939 o primeros de 1840. Las dimensiones de la encuadernación son 151 × 100 x $28 \mathrm{~mm}$., su signatura es 3385/1840-1 y forma parte de la Biblioteca Adolfo Herrera.

El análisis de la encuadernación nos indica que las tapas son de cartón y están recubiertas de tafilete color marrón, al igual que el lomo, las guardas son de papel verjurado y marmoleado con colores azul, gris, negro y rojo, los nervios son de cordel de fibra vegetal y los cortes están pintados de color amarillo. 
En la estructura constructiva los aspectos más destacables es que las tapas no están encartonadas sino que son sueltas, el lomo es liso y recto, el cosido está realizado con la técnica denominada a punto salteado o a la francesa y a la greca, las guardas están marmoleadas mediante el traspaso por el contacto de la pintura en la superficie de un líquido mucilaginoso.
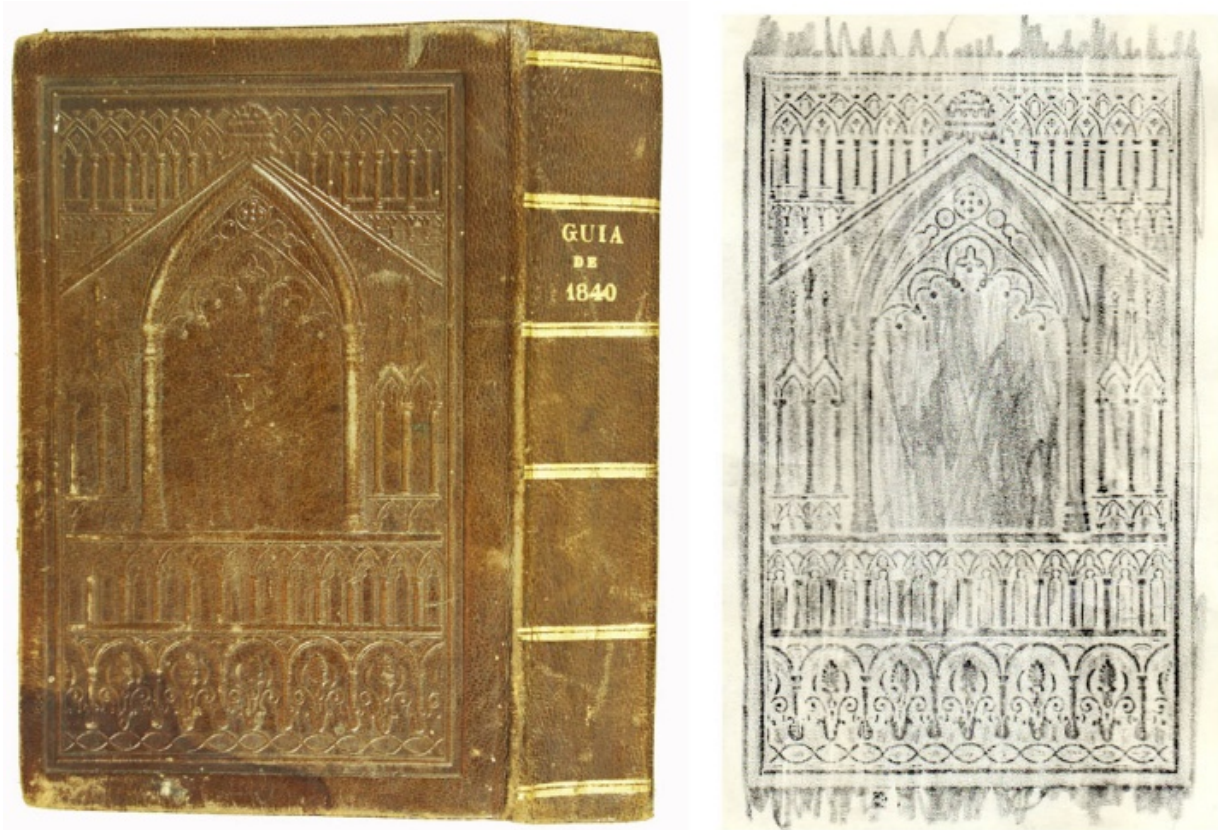

Fig. 5. Tapa posterior y lomo y frotis de la plancha

Respecto a la estructura decorativa indicar que es simétrica y se compone de una plancha de tipo a la catedral (133 x $82 \mathrm{~mm}$.), que ocupa toda la superficie de la tapa, decorada con un gran ventanal en el centro y pequeños ventanales en la parte superior, inferior y a ambos lados. Esta plancha central también la encontramos en otra encuadernación de la Real Biblioteca (sig. CS/4/1) del año 1839. El utensilio empleado ha sido una plancha y la técnica decorativa el gofrado. El diseño de las guardas forma parte del modelo del grupo denominado gotas y del modelo plegado español o españo ${ }^{\not}$. El lomo está decorado con paletas de dos hilos dorados, uno de ellos más ancho, imitando los nervios y en uno de los entrenervios aparece la leyenda "GUIA / DE / 1840", todo ello dorado. Los cortes están pintados de color amarillo.

\footnotetext{
${ }^{8}$ El diseño consiste simplemente en dejar la pintura tal y como cae en el líquido, posteriormente se realizan movimientos hacia delante y hacia atrás del papel en contacto con el líquido realizándose una serie de líneas que le confieren un cierto movimiento al diseño.
} 
El estado de conservación es bueno, sin embargo presenta deformación en las puntas, abrasiones en el lomo y cantos y rasgaduras del papel de las guardas en la zona de la bisagra.

La siguiente encuadernación contiene la Guía de forasteros en Madrid, para el año de 1841, realizada por el taller de Miguel Ginesta Clarós a finales de 1840 o primeros de 1841. Sus dimensiones son 151 x 100 x $28 \mathrm{~mm}$. y su signatura es $21 / 1841$.

Una vez realizado el análisis de la encuadernación encontramos que las tapas son de cartón y están recubiertas de tafilete color marrón, al igual que el lomo, las guardas son de papel verjurado y marmoleado con colores azul, gris, negro y rojo y los nervios son de cordel de fibra vegetal.
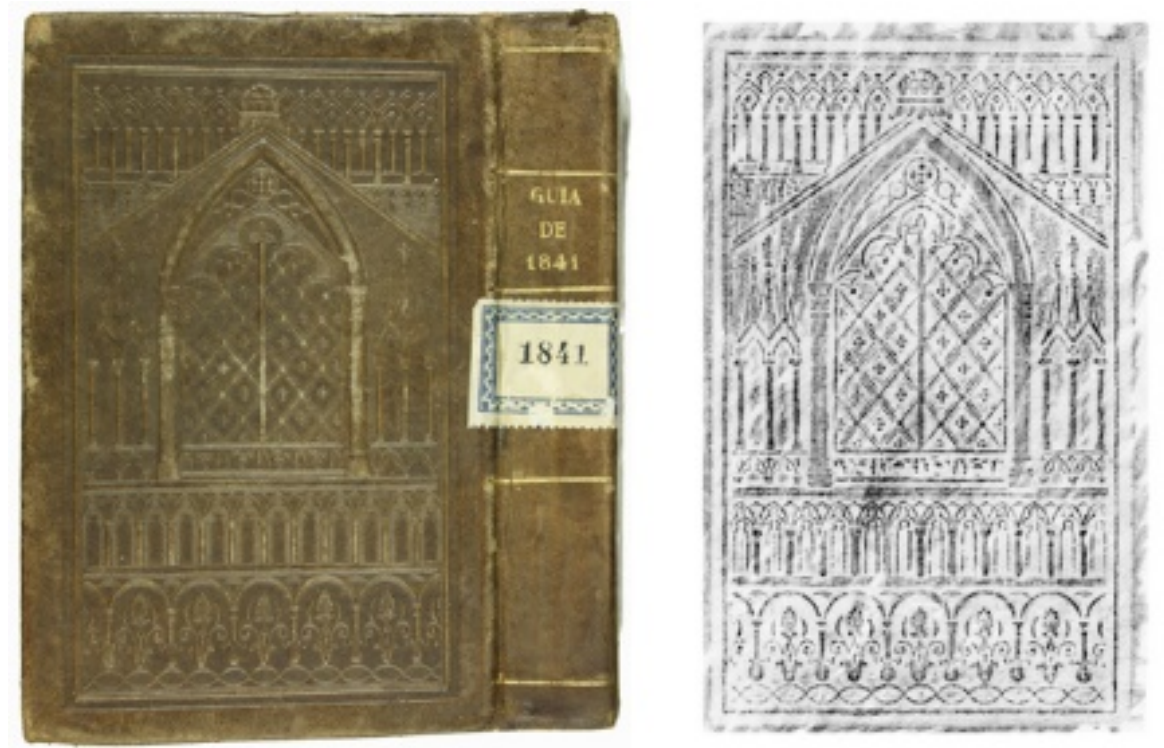

Fig. 6. Tapa posterior y lomo y frotis de la plancha

En cuanto a las técnicas constructivas el análisis nos indica que las tapas no están encartonadas sino que son sueltas, el lomo es liso y recto, el cosido está realizado con la técnica denominada a punto salteado o a la francesa y a la greca y las guardas están marmoleadas mediante el traspaso por el contacto de la pintura en la superficie de un líquido mucilaginoso.

La estructura decorativa de las tapas es simétrica y se compone de una plancha de tipo a la catedral (133 x $82 \mathrm{~mm}$.), que ocupa toda la superficie de la tapa, 
decorada con un gran ventanal en el centro y pequeños ventanales en la parte superior, inferior y a ambos lados. Esta plancha la encontramos también en otra encuadernación custodiada en la Real Biblioteca (sig. CS/4/2) del año 1842. El utensilio empleado ha sido una plancha y la técnica decorativa el gofrado. El diseño de las guardas forma parte del grupo denominado gotas y del modelo plegado español o español. El lomo está decorado con paletas de un hilo dorado, imitando los nervios y en uno de los entrenervios aparece la leyenda "GUIA / DE / 1840", todo ello dorado.

El estado de conservación es bueno, sin embargo, presenta deformación en las puntas, abrasiones en el lomo y cantos; y pequeñas roturas del papel en la zona de la bisagra de ambas guardas.

La siguiente encuadernación a estudio contiene la Guía de forasteros en Madrid, para el año de 1843, realizada también por Miguel Ginesta Clarós, a finales de 1843 o primeros de 1844. Las dimensiones de la encuadernación son 151 x 100 x $28 \mathrm{~mm}$. y su signatura es $21 / 1843$.

Los materiales empleados para su construcción han sido cartón para las tapas y el lomo, recubiertas de tafilete color marrón, las guardas son de papel verjurado y marmoleado con colores azul, gris, negro y rojo y los nervios son de cordel de fibra vegetal.

Respecto a las técnicas de construcción el análisis nos indica que las tapas no están encartonadas sino que son sueltas, el lomo es liso y recto, el cosido está realizado con la técnica denominada a punto salteado o a la francesa y a la greca y las guardas están marmoleadas mediante el traspaso por el contacto de la pintura en la superficie de un líquido mucilaginoso. 

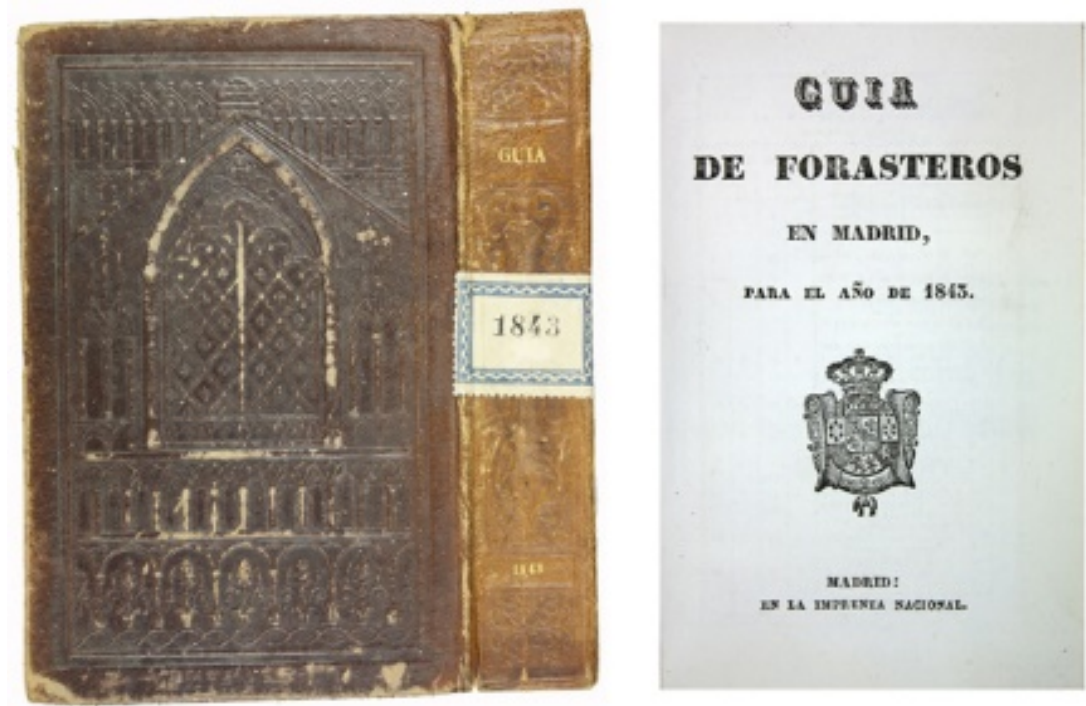

Fig. 7. Tapa posterior y lomo y portada

La estructura decorativa de las tapas es simétrica y se compone de una plancha de tipo a la catedral (133 x $82 \mathrm{~mm}$.), que ocupa toda la superficie de la tapa, decorada con un gran ventanal en el centro y pequeños ventanales en la parte superior, inferior y a ambos lados. El utensilio empleado ha sido una plancha y la técnica decorativa el gofrado. El diseño de las guardas forma parte del grupo denominado gotas y del modelo plegado español o español. El lomo está decorado con una plancha romántica gofrada con dos espacios, uno en la parte superior con la leyenda dorada "GUIA" y en la parte inferior "1843".

El estado de conservación es bueno, sin embargo presenta deformación en las puntas, abrasiones en el lomo y cantos, y pequeñas roturas del papel en la bisagra de ambas guardas.

Las tres planchas anteriores son muy similares, con el añadido que en las dos últimas (sig. 21/1841 y 21/1843) contienen un enrejado en el ventanal que no aparece en la primera (sig. 3385/1840-1).

La siguiente encuadernación contiene la obra Historia de la Santa Reliquia que con el título del Santo Dubio se venera en la iglesia parroquial de San Benito Abad, en la villa de Yepes..., publicada por D. Julián Luis María Arranz en Madrid en la Imprenta de la Regeneración en 1857. En la portada estampado en el sello: "Real Academia de la Historia-Fondo Ángel Ferrari". Las dimensiones de la encuadernación son $175 \times 120 \times 13 \mathrm{~mm}$. y su signatura es 23/15579. La encuadernación fue realizada por Miguel Ginesta de Haro. 

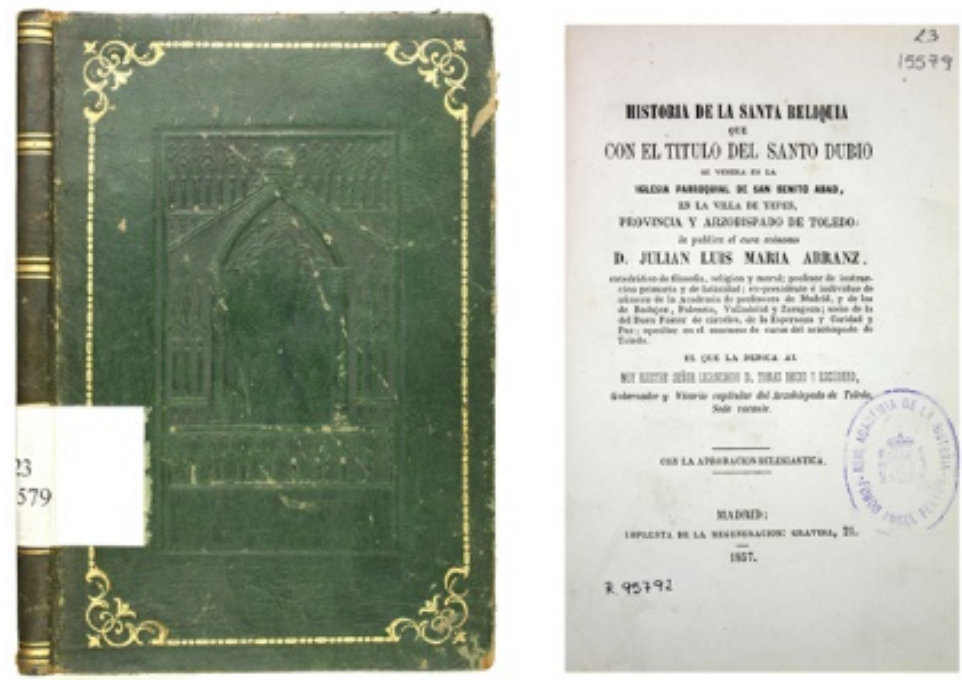

Fig. 8. Tapa posterior y lomo y portada

El estudio sobre los materiales empleados nos indica que las tapas son de cartón recubiertas de piel de color marrón, al igual que el lomo, las guardas son de papel con fondo blanco con motivos punteados, los nervios son de cordel de fibra vegetal y los cortes están decorados con pan de oro.

En cuanto a las técnicas constructivas se observa que las tapas están encartonadas mediante dos nervios sencillos, con un cosido a punto seguido y a la greca, el lomo es liso y está redondeado y las guardas están realizadas con papel industrial de motivos geométricos.

Respecto a la decoración indicamos que las tapas son simétricas y están decoradas con un encuadramiento exterior compuesto por una rueda dorada de postas irregulares, rematada con un florón de motivos redondeados, en cada una de las esquinas. La parte central está decorada con una plancha gofrada a la catedral (135 x 59). La plancha central la encontramos en otra encuadernación de la Biblioteca Histórica Municipal de Madrid (sig. R 708) (Carpallo Bautista 2015). Los utensilios empleados han sido una rueda, un hierro suelto y una plancha y las técnicas de decoración el gofrado y el dorado. Las guardas están decoradas con papel industrial de figuras geométricas punteadas. El lomo está decorado con una paleta dorada de triple filete; el central más grueso que los laterales. Los cortes están dorados. La encuadernación se encuentra en buen estado, aunque con rozaduras en las tapas y cantos del libro. 
La encuadernación siguiente contiene la obra Flavius Vegetius... enundantura., impresa en Paris por Johane parvo en 1515, por lo tanto su encuadernación no es original de la época. Sus dimensiones son 197 × 137 x 19 mm., su signatura es 2/1531 y forma parte de la Biblioteca Marqués de San Román, tal y como se indica en la guarda anterior con el sello de "Biblioteca E.F. San Román" y en la portada con el sello estampado "R. Academia de la Historia. Biblioteca. San Román”.

En el presente estudio en una de estas encuadernaciones artísticas encontramos que los materiales utilizados las tapas son de cartón recubiertas de piel de color marrón, al igual que el lomo, las guardas son de papel de fondo blanco con pintura de color amarillo, azul, verde, rojo y blanco, los nervios son de cordel de fibra vegetal y los cortes están teñidos con pintura marrón.

En cuanto a las técnicas de construcción indicar que las tapas están encartonadas mediante tres nervios sencillos, con un cosido a punto seguido y a la greca, el lomo es liso y está redondeado, las guardas son del tipo marmoleado, realizadas mediante el traspaso por contacto de la pintura en la superficie de un líquido mucilaginoso contenido en una cubeta y los cortes han sido teñidos.
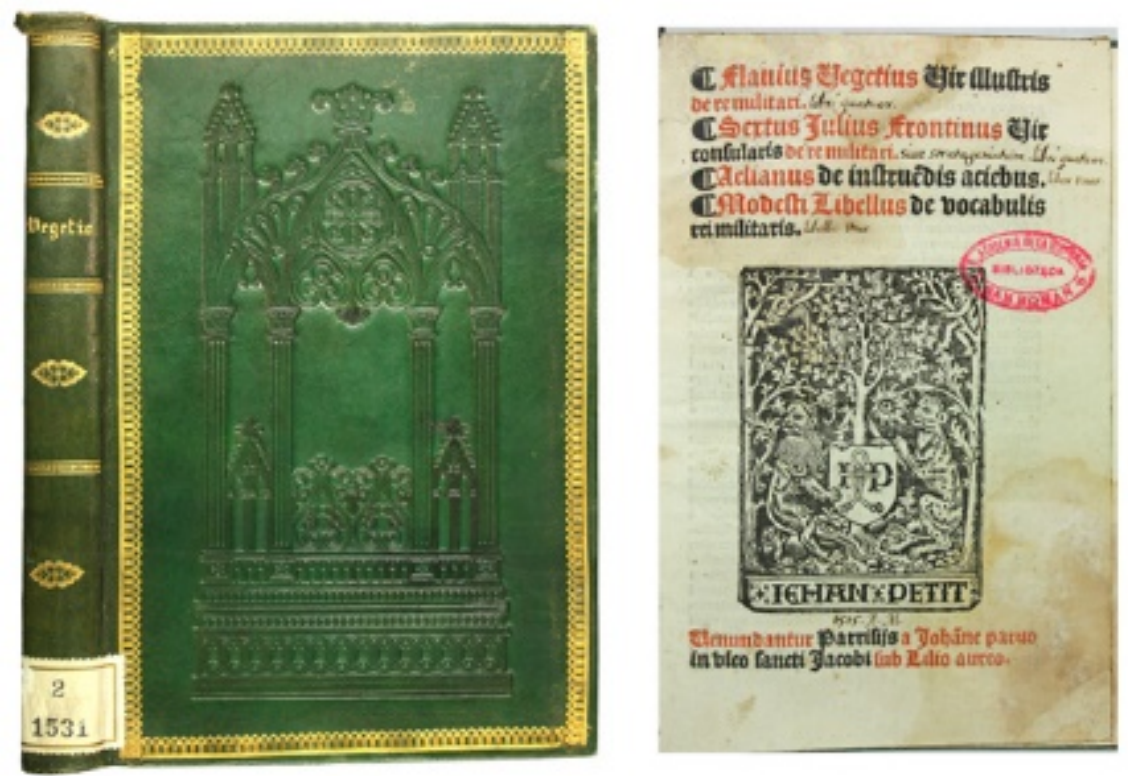

Fig. 9. Tapa anterior y lomo y portada 
En el estudio de la estructura decorativa destaca que la ornamentación de las tapas es simétricas y están decoradas por un encuadramiento exterior formado por: una rueda dorada de doble hilo; una rueda dorada de arcos y un hilo dorado ondulado. La parte central está decorada con una planta gofrada a la catedral (165 x $88 \mathrm{~mm}$.). Los utensilios empleados han sido tres ruedas y una plancha y las técnicas de decoración el dorado y el gofrado. Las guardas están decoradas siguiendo el grupo denominado gotas o modelo plegado español. El lomo está decorado con un florón dorado en horizontal. Los nervios están decorados con una paleta dorada de pequeños motivos dentro de un hilo dorado y los cantos con una rueda dorada de hilo ondulado con pequeñas florecillas. El tejuelo contiene la leyenda: "VEGETIO". Los cortes están decorados con el teñido de pintura marrón. La encuadernación se encuentra en buen estado, con algunas rozaduras superficiales.

Esta misma plancha la encontramos en una encuadernación firmada en la parte inferior del lomo por Wagner (Culot 1997) sobre una edición de Amable Tastu titulada Poésies publicada en Paris en 1827. En esta ocasión la plancha se muestra dorada.

Otra de las encuadernaciones que tenemos con una plancha central tipo a la catedral contiene la obra Historia de la dominación de los árabes en Murcia, sacada de los mejores autores, y de una multitud de códices y documentos auténticos de aquella época... de Félix Ponzoa Cebrián, publicado en Palma de Mallorca por la Imprenta Nacional a cargo de Juan Guasp en 1845. Sus dimensiones son 228 x 156 x 25 mm. y su signatura es 3/8814. En la portada estampado el sello "Real Academia de la Historia - Biblioteca". 

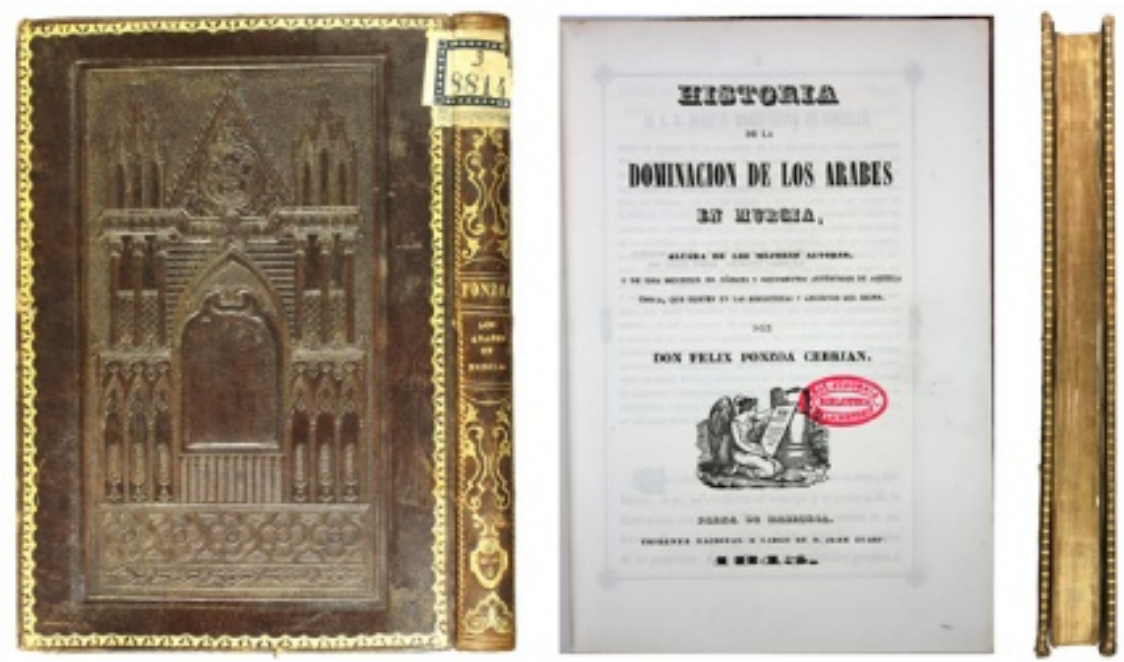

Fig. 10. Tapa posterior y lomo, portada y corte delantero

El análisis completo de los materiales de construcción nos indica que las tapas son de cartón recubiertas de piel de color granate, al igual que el lomo, las guardas son de papel moaré, de color blanco, los nervios son de cordel de fibra vegetal, el núcleo de las cabezadas es una tira de cordel de fibra vegetal recubierta de tela de color morado y los cortes están decorados con pan de oro.

En cuanto a las técnicas de construcción indicamos que las tapas están encartonadas mediante tres nervios sencillos, con un cosido a punto seguido y a la greca y el lomo es liso y está redondeado.

Las tapas son simétricas y están decoradas por un encuadramiento exterior formado por una rueda dorada de guirnaldas. La parte central está decorada con una planta gofrada a la catedral (185 x $105 \mathrm{~mm}$.). Los utensilios empleados han sido una rueda y una plancha y las técnicas de decoración el dorado y el gofrado. Las guardas están decoradas con papel moaré, de color blanco. El lomo está decorado con hierros dorados románticos, con un hierro de rostro humano y con una rueda de hilo en zig-zag que lo flanquea. El tejuelo contiene la leyenda: "PONZOA / LOS / ARABES / EN / MURCIA". Los cantos están decorados con una rueda dorada de pequeños hilos en paralelo y la cofia con una paleta dorada de hilos en paralelo. Las cabezadas están decoradas con el recubrimiento de tela de color morado. Los cortes están dorados. La encuadernación se encuentra en buen estado, con algunas rozaduras superficiales. 
La encuadernación que estudiamos a continuación contiene, de nuevo una Guía de forasteros en Madrid, para el año de 1838. Sus dimensiones son $150 \mathrm{x} 102 \mathrm{x}$ $31 \mathrm{~mm}$. y su signatura es 21/1838-2. Esta plancha la podemos encontrar en dos encuadernaciones custodiadas en la Real Biblioteca (sig. XIV/2911 y I/I/290), realizadas por el encuadernador Antonio Suárez Jiménez. También encontramos referencias a una plancha similar con pequeñas variantes en un artículo de López Serrano (1942), indicando que perteneció a la antigua colección de Vicente Castañeda, adquirida en 1941 por el XVII duque de Alba, Jacobo Fitz-James Stuart y Falcó, y en la actualidad en el Palacio de Liria.

Esta encuadernación posiblemente fuese realizada por Pedro Pastor, a finales de 1937 o primeros de 1838, quien compra parte del taller de Antonio Suárez a su muerte en 1836.
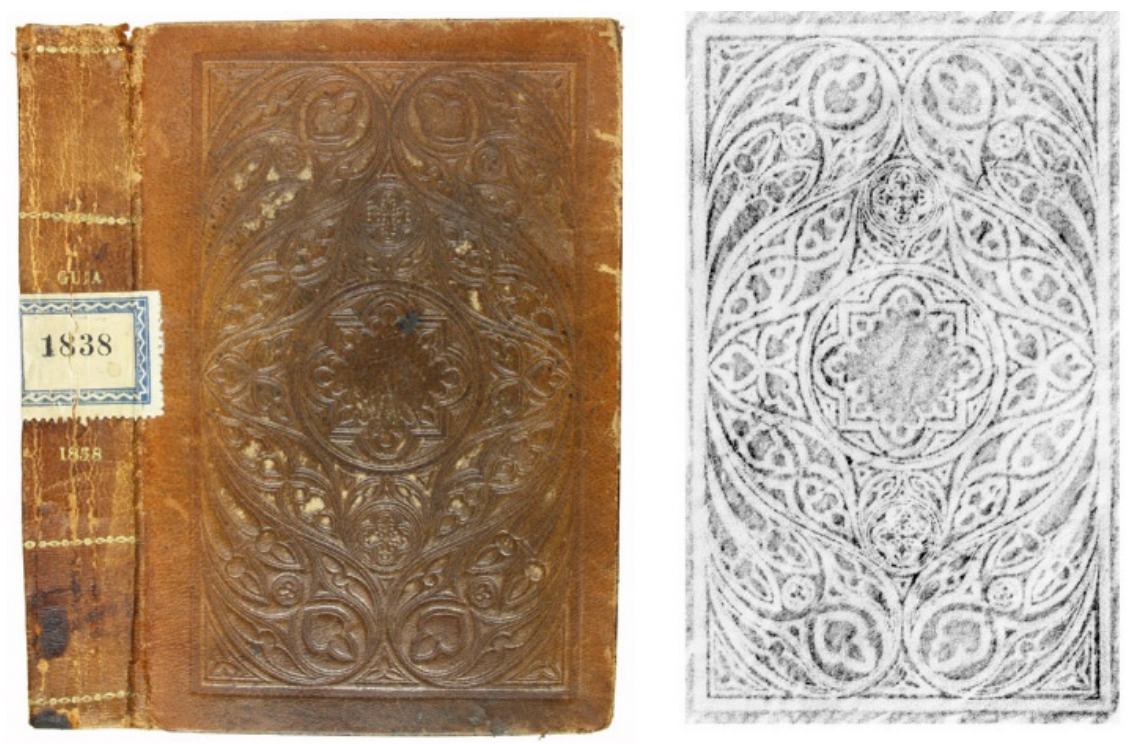

Fig. 11. Tapa anteriory lomo y frotis de la plancha

El análisis de los materiales empleados nos indica que las tapas son de cartón y están recubiertas de tafilete color marrón, al igual que el lomo, las guardas son de papel verjurado y marmoleado con colores azul, gris y rosa, los nervios son de cordel de fibra vegetal y los cortes están pintadas con tinta de color amarillo.

En cuanto a las técnicas de construcción indicamos que las tapas no están encartonadas sino que son sueltas, el lomo es liso y recto, el cosido está realizado con la técnica denominada a punto salteado o a la francesa y a la 
greca y las guardas están marmoleadas mediante el traspaso por el contacto de la pintura en la superficie de un líquido mucilaginoso.

La estructura decorativa de las tapas es simétrica y se compone de una plancha de tipo romántico a la catedral $(135 \times 82 \mathrm{~mm}$.), que ocupa toda la superficie de la tapa, decorada con un rombo lobulado en el centro, dentro de un cuadrado con las bandas lobuladas y todo ello dentro de un círculo; el resto de los espacios de la plancha están ornamentados con elementos geométricos estilizados que nos recuerdan pequeños ventanales de catedrales góticas. El utensilio empleado ha sido una plancha y la técnica decorativa el gofrado. El diseño de las guardas forma parte del modelo el modelo denominado gotas y del grupo plegado español o español. El lomo está decorado con paletas de pequeños rombos y circulillos alternados que imitan los nervios, junto a la leyenda en los dos entrenervios intermedios "GUIA / 1838", todo ello dorado. Los cortes están decorados con tinta de color amarillo.

El estado de conservación es bueno, aunque las tapas presentan alguna deformación en las puntas, abrasiones en el lomo, tapas y cantos, manchas en la parte inferior del lomo y rotura de la piel en la cofia superior, y pequeñas roturas del papel en la zona de la bisagra de la guarda anterior.

Esta última encuadernación contiene la Guia de forasteros en Madrid, para el año de 1842, realizada a finales de 1842 o primeros de 1842. Sus dimensiones son 152 x 104 x $31 \mathrm{~mm}$. y su signatura es 21/1842.

Los materiales utilizados en su construcción han sido el cartón para las tapas y recubiertas de tafilete color verde, al igual que el lomo, las guardas son de papel verjurado y marmoleado con colores azul, gris, negro y rojo, los nervios son de cordel de fibra vegetal y los cortes están salpicados con gotas de color rojo.

En cuanto a las técnicas de construcción indicamos que las tapas no están encartonadas sino que son sueltas, el lomo es liso y recto, el cosido está realizado con la técnica denominada a punto salteado o a la francesa y a la greca y las guardas están marmoleadas mediante el traspaso por el contacto de la pintura en la superficie de un líquido mucilaginoso. 

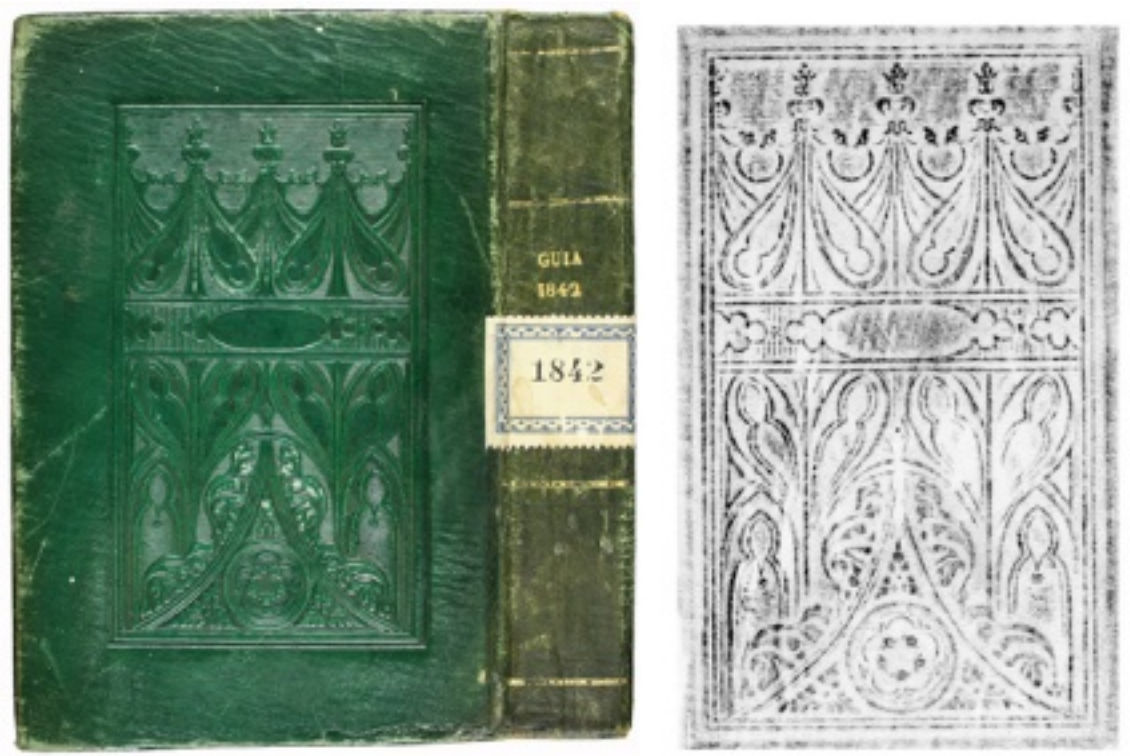

Fig. 12. Tapa posterior y lomo y frotis de la plancha

La estructura decorativa de las tapas es simétrica y se compone de una plancha de tipo a la catedral (111 x $67 \mathrm{~mm}$.), que ocupa la superficie central de la tapa, decorada con formas geométricas que imitan los ventanales de las catedrales góticas junto a una flor de cinco pétalos en la parte inferior de la plancha. Similar a esta plancha central encontramos otra en una encuadernación de la Biblioteca de la Real Academia de Bellas Artes de San Fernando (sig. C-1879) resguardando una Guía de forasteros de 1842. El utensilio empleado ha sido una plancha. La técnica decorativa empleada ha sido el gofrado. El diseño de las guardas forma parte del grupo denominado gotas y del modelo plegado español o español. El lomo está decorado con paletas de un hilo dorado imitando los nervios y en uno de los entrenervios aparece la leyenda “GUIA / 1842”, todo ello dorado. Los cortes están decorados con gotas de color rojo.

El estado de conservación es bueno, sin embargo, presenta abrasiones en el lomo, tapas y cantos, y pequeñas roturas de papel en la zona de la bisagra de ambas guardas.

\section{Conclusiones}

Por el estudio realizado encontramos que estas encuadernaciones, en su mayoría realizadas por encuadernadores españoles, contienen reproducciones de planchas ya utilizadas, principalmente en Francia, durante el siglo XIX (2/1531). También encontramos planchas empleadas en un mismo taller (por 
ejemplo, en el taller de Ginesta) a lo largo de varias décadas donde se incluyen pequeñas variantes en su decoración como las planchas en las signaturas $1 / 2987,3 / 7027$ y $19-2 / 510$ y otras como las signaturas 23/15579, 3385/1840-1, 21/1841 y 2/1843. El estudio de las planchas, hierros del lomo, ornamentación de las guardas y estructuras constructivas, junto al estudio comparativo con encuadernaciones similares que forman parte de otras colecciones, nos ha ayudado a identificar la autoría de varias de ellas realizadas en el taller de Ginesta, seis de ellas por Miguel Ginesta Clarós (sig. 19-2/510, 3385/1840-1, 21/1841, 2/1843, 1/2987 y 3/7027), y una por Miguel Ginesta de Haro (sig. 23/15579). También otra realizada con una plancha que perteneció a Antonio Suárez Jiménez y que pudo acabar en el taller de Pedro Pastor por la compra de parte del taller a la muerte de Suárez en 1836.

Desde el punto de vista de la estructura constructiva coinciden las encuadernaciones encartonadas con una costura a punto seguido (sig. 1/2987, $3 / 7027,23 / 15579,2 / 1531$ y $3 / 8814$ ) y las encuadernaciones de tapa suelta con la costura a punto salteado (sig. 19-2/510, 3385/1840-1, 21/1841, $21 / 1843,21 / 1838-2$ y $21 / 1842$ ), aunque la gran mayoría contienen guardas marmoleadas tipo plegado español o Shell. En todas las planchas de las encuadernaciones se ha empleado la técnica del gofrado, algo más usual en las encuadernaciones españolas y menos en las del centro de Europa, principalmente en Francia.

También encontramos diversidad de marcas de propiedad, debido a que esta biblioteca contiene numerosos fondos y colecciones donadas por antiguos académicos y personalidades de la vida política y cultural española como Alfonso de Falco y de la Gándara, Príncipe Pio de Saboya, Eduardo Fernández San Román, marqués de San Román, Ángel Ferrari Núñez y Adolfo Herrera.

\section{Bibliografía}

ALBEROLA FIORAVANTI, M. V., 1996. La Biblioteca de la Real Academia de la Historia. Encuadernación de arte, 7, 21-35. ISSN 1133-1860.

BERALDI, H., 1895. La reliure du XIXe siècle. Paris: L. Conquet. 
BERMEJO, J.B. (dir). 1998. Enciclopedia de la encuadernación. Madrid: Ollero y Ramos. ISBN 978-84-7895105-5.

CAPELA MARTÍNEZ, M., 1963. Las artes gráficas madrileñas en el siglo XIX. En: La industria en Madrid: ensayo bistórico crítico de la fabricación y la artesanía madrileñas: siglos XVIII al XIX desde 1701 a 1912: la industria en Madrid del siglo XIX. Madrid: Artes Gráficas y Ediciones, pp. 573-589.

CARPALLO BAUTISTA, A., 2015. Encuadernaciones del siglo XIX en la Biblioteca Histórica Municipal de Madrid. Madrid: Ollero y Ramos. ISBN 978-84-7895-2946.

CARPALLO BAUTISTA, A. et al. 2015. Encuadernaciones de las Guías de forasteros de la Real Academia de la Historia. Madrid: Ollero y Ramos. ISBN 978-84-7895-295-3.

CARRIÓN GÚTIEZ, M., 1996. La encuadernación española en los siglos XIX y XX. En: Historia ilustrada del libro español: la edición moderna. Madrid: Fundación Germán Sánchez Ruipérez: Pirámide, pp. 491-539. ISBN 84-368-1014-7.

CULOT, P., 1997. Relieurs et reliures décorées en France à l'époque romantique: supplément. Paris: Bibliothèque historique de la Ville de Paris. ISBN 2-84331-013-X.

CULOT, P., 2000. Relieurs et reliures décorées en France aux époques Directoire et Empire. Bruxelles: Bibliotheca Wittockiana. ISBN 978-906194939-8.

DEVEAUX, Y., 2014. Les frères Bozerian. Ars \& Metiers du Livre, 305, 84-85. ISSN 1626-9594.

DEVEAUX, Y., 2015. Les reliures romantiques: Thouvenin, Simier et quelques autres. Art \& Métiers du Livre, 306, 30-39. ISSN 1626-9594.

GARCÍA HERRANZ, A. y CARPALLO BAUTISTA, A., 2015. Brugalla, maestro encuadernador, en la Biblioteca de la Real Academia de la Historia. Madrid: Real Academia de la Historia. ISBN 978-84-1506951-5.

GILLES, K., 2014. Les reliures “à la cathédrale”. Art \& Métiers du Livre, 302, 84-85. ISSN 1626-9594.

LÓPEZ SERRANO, M., 1942. Libreros encuadernadores de cámara. I. Antonio Suárez. Arte Español, XIV, 27(2-3), 7-14. ISSN 9944-2930.

LÓPEZ SERRANO, M., 1943. Libreros encuadernadores de cámara. II. Santiago Martín, Arte Español, XIV, 27(4), 14-22. ISSN 9944-2930.

LÓPEZ SERRANO, M., 1975. Gabriel de Sancha: editor, impresor y encuadernador madrileño (1746-1820). Madrid: Ayuntamiento: Instituto de Estudios Madrileños. ISBN 84-239-4553-7. 
MASSÓ VALDÉS, J. B. y CARPALLO BAUTISTA, A., 2017. Estudio e identificación de las encuadernaciones de tipo imperio del siglo XIX de la Real Academia de la Historia. Anales de Documentación, 20(1). ISSN 1697-7904. http://dx.doi.org/10.6018/analesdoc.20.1.262111.

RUIZ, E., 1997. Catálogo de la sección de códices de la Real Academia de la Historia. Madrid: Real Academia de la Historia. ISBN 84-89512-03-5. 